\title{
A ubiquitous factor is required for C/EBP-related proteins to form stable transcription complexes on an albumin promoter segment in vitro
}

\author{
Patrice M. Milos and Kenneth S. Zaret \\ Section of Biochemistry, Brown University, Providence, Rhode Island 02912 USA
}

\begin{abstract}
The liver-enriched transcription factor CCAAT/enhancer binding protein (C/EBP) binds to numerous liver-specific promoters, yet the mechanism by which the protein stimulates transcription has not been described. The serum albumin promoter, which is liver specific, contains a strong C/EBP-binding site tightly juxtaposed to a binding site for the ubiquitous factor nuclear factor-Y (NF-Y). The binding of C/EBP impairs the binding of NF-Y; yet surprisingly, this arrangement leads to strong synergistic activation of a minimal promoter in liver nuclear extracts. Transcriptional synergism is manifested by NF-Y facilitating the ability of C/EBP to form preinitiation complexes that are stable through multiple rounds of transcription. Binding by itself, C/EBP stimulates transcription weakly without forming stable complexes, and moving the NF-Y binding site $10 \mathrm{bp}$ away from the C/EBP site increases NF-Y binding in the presence of C/EBP but reduces the efficiency of stable complex formation and transcriptional synergism. These findings show that $\mathrm{C} / \mathrm{EBP}$ requires precise positioning next to a ubiquitous factor for optimal formation of stable complexes and provides a model to understand the dramatic activation of the albumin gene in hepatic development.
\end{abstract}

[Key Words: Transcription factors; synergism; liver differentiation; C/EBP; NF-Y]

Received February 14, 1992; revised version accepted April 2, 1992.

Genes can be transcribed at different frequencies by binding regulatory factors in distinct combinations, yet how such factors interact to stimulate the rate of transcriptional initiation has remained elusive. Creating polymers of single factor-binding sites, which by themselves may have weak or no stimulatory activity, can often cause strong transcriptional stimulation (Ondek et al. 1987; Schirm et al. 1987). The fact that such synergistic effects can occur when regulatory proteins saturate their binding sites on DNA demonstrates that a critical mass of activator protein may be necessary to effectively stimulate the basic transcriptional machinery (Carey et al. 1990; Oliviero and Struhl 1991). However, interactions between different factors that bind to a complex regulatory element can lead to much greater transcriptional stimulation than multimers of individual factors that bind the same sequence (e.g., Fromental et al. 1988). For example, the six closely spaced, different factor-binding sites upstream of the TATA sequence of the serum albumin gene cause much greater transcriptional activation in vitro than 4- to 12-fold multimers of any of the individual binding sites (Maire et al. 1989). Thus, there appear to be functional differences in the roles played by factors binding in particular combinations compared with those binding by themselves. As an initial step in understanding this phenomenon, we have investigated how two different factors that bind to the albumin promoter interact and thereby change their respective contributions to promoter activity. The findings provide a model for understanding how the albumin gene is transcribed at such a dramatically greater rate in liver than in other tissues of the mouse (Liu et al. 1988).

The albumin gene promoter and enhancer, both of which are liver specific in functional assays (Ott et al. 1984; Gorski et al. 1986; Pinkert et al. 1987; Zaret et al. 1988), bind an array of liver-enriched and cell-ubiquitous transcription factors (Babiss et al. 1987; Cereghini et al. 1987; Lichtsteiner et al. 1987; Herbst et al. 1989; Liu et al. 1991). Liver-enriched factors binding to the albumin promoter include $\mathrm{HNF} 1 \alpha$, a homeo box-related protein which is abundant in liver and kidney and binds to the pB site (Cereghini et al. 1988; Courtois et al. 1988; Frain et al. 1989), and the CCAAT/enhancer binding protein (C/EBP) family of proteins, which are related by their basic amino acid regions and leucine zippers (Landschulz et al. 1988) and bind to the $\mathrm{pD}$ site. $\mathrm{pD}$ site-binding proteins include C/EBP, which is abundant in liver and fat (Johnson et al. 1987; Birkenmeier et al. 1989), and DBP (Mueller et al. 1990) and LAP/IL6-DBP/CRP2 (Descombes et al. 1990; Poli et al. 1990; Cao et al. 1991; Williams et al. 1991), which appear liver specific; we refer to these factors collectively as C/EBP-related pro- 
teins (CRPs; Williams et al. 1991). C/EBP and LAP/IL6DBP represent virtually all CRP-binding activity to the $\mathrm{pD}$ site in liver nuclear extracts isolated from rodents in the middle of the day, and these factors can heterodimerize in vitro (Descombes et al. 1990; Poli et al. 1990; Cao et al. 1991) and in vivo (Williams et al. 1991). Another critical factor for the albumin promoter is nuclear factor-Y (NF-Y), which binds the $\mathrm{pC}$ site containing the CCAAT sequence (Raymondjean et al. 1988). NF-Y is a heterodimer of two subunits that are homologous to the yeast HAP2 and HAP3 activators (Olesen and Guarente 1990) and is found in all tissues examined (Hooft van Huijsduijnen et al. 1990; Maity et al. 1990).

Previous DNase I footprinting studies suggested that there were unusual interactions between the NF-Y factor and CRPs, because the individual footprints for these factors were partially overlapping (Cereghini et al. 1987; Lichtsteiner et al. 1987). In crude liver nuclear extracts, the CRP footprint at the $\mathrm{pD}$ site predominated and the $\mathrm{pC}$ footprint was barely evident. However, the $\mathrm{pC}$ site was protected efficiently by NF-Y when CRP factors were removed by chromatography. These findings, along with the fact that maximal promoter activity in transfected hepatoma cells (Herbomel et al. 1989) and in liver nuclear extracts (Lichtsteiner et al. 1987; Wuarin et al. $1990)$ required both the $\mathrm{pC}$ and $\mathrm{pD}$ sites, suggested that these factors functioned either sequentially or interacted in an unusual fashion to activate transcription. The importance of the interactions between these factors is underscored by the very weak activity of the albumin promoter in nonliver cells and extracts that contain NF-Y but lack CRP (Lichtsteiner et al. 1987; Herbomel et al. 1989; Wuarin et al. 1990).

In this paper we specifically address how CRP and NF-Y affect the ability of one another to bind to DNA and to stimulate transcription. We studied the function of intact $\mathrm{pC}$ - and $\mathrm{pD}$-binding sites separated from the rest of albumin upstream elements with an in vitro transcription system derived from liver nuclear extracts. The system allowed us to collectively examine the activities of C/EBP and LAP/IL6-DBP and to dissect the relative roles of CRP and NF-Y in the transcription initiation process. Surprisingly, we found that precise positioning of the ubiquitous factor induced the liver-enriched factors to have a new activity - the ability to assemble preinitiation complexes at the promoter that are stable through multiple rounds of transcription. We defined the parameters required for this reaction and suggest how such interactions explain part of the very high level of activation of the albumin promoter during hepatocyte differentiation.

\section{Results \\ C/EBP-related proteins and NF-Y synergistically activate transcription}

The plasmid pTOS8-WT was created to study interactions between CRP and NF-Y isolated from other factors binding to the mouse albumin promoter; it contains the
$\mathrm{pD}$ and $\mathrm{pC}$ sites $(-110$ to -69$)$ linked to the albumin TATA element and transcription start site $(-54$ to +8$)$ (Fig. 1A). Plasmids containing albumin $5^{\prime}$ promoter segments deleted to -58 were shown previously by Gorski et al. (1986) to retain only $1 \%$ of transcriptional activity in vitro, compared with the wild-type promoter. In addition to the wild-type template, promoter segments $(-110 /-69)$ mutated for the CRP site (M1), the NF-Y site (M2), or both sites $(M 3)$ were ligated to the TATA element in both orientations; all fusions were placed in front of the bacterial neo gene. In vitro transcription reactions included an internal control plasmid consisting of either pTN3, containing a truncated thymidine kinase $(t k)$ promoter linked to the neo-coding sequence, or pST1, with the SV40 early promoter driving the $t k$-coding sequence. RNA synthesized in each reaction was analyzed by a primer extension assay, and transcription products that initiated at the correct start sites were quantitated.

The plasmid containing both the CRP site and the NF-Y site in their natural orientation (WT) showed an average of 42-fold transcriptional stimulation over the pTOS8-M3 plasmid, which had both binding sites mutated (Fig. 1B,C). (The effects of the mutations on DNA binding are confirmed below; see Fig. 2A.) Strikingly, mutation of the CRP site (PTOS8-M1), leaving the NF-Y site intact, reduced promoter stimulation to 9.7-fold (Fig. $1 \mathrm{C})$ over M3, whereas mutation of the NF-Y site, leaving the CRP site intact, reduced promoter stimulation to 3-fold (Fig. 1C). The transcriptional activation generated by the plasmid containing both binding sites (pTOS8WT) was much greater than the sum of activities of plasmids with individual sites, indicating synergism (Fig. 1C). Thus, the binding sites for both factors clearly function in a positive manner, as shown for the intact promoter in vitro by Lichtsteiner et al. (1987). Identical transcriptional signals were observed with the TOS8 fragments in the inverted orientation (data not shown), demonstrating that synergism was not dependent on a precise arrangement of CRP and NF-Y on the template relative to the TATA element.

\section{CRP and NF-Y form a ternary complex with DNA}

To address the means by which these two factors synergize, we reevaluated the ability of the proteins to bind DNA simultaneously (Lichtsteiner et al. 1987). Electromobility-shift assays (EMSAs) were performed with liver nuclear extracts and oligonucleotides of the TOS8-WT, $-\mathrm{M} 1$, and -M2 sequences (Fig. 2A). A major binding activity, seen with the TOS8-WT probe, is a slowly migrating protein-DNA complex, here labeled $\mathrm{C} / \mathrm{Y}$. This contrasts with the TOS8-M1 probe, which forms a faster mobility complex characteristic of NF-Y (Raymondjean et al. 1988). Factors binding to the TOS8-M2 probe give rise to a smear that also migrates faster than the $\mathrm{C} / \mathrm{Y}$ complex; the pattern is expected for the homo- and heterodimeric members of the C/EBP family of proteins, C/EBP and LAP/IL6-DBP (Descombes et al. 1990; Poli et al. 1990; Cao et al. 1991; Williams et al. 1991). 
A

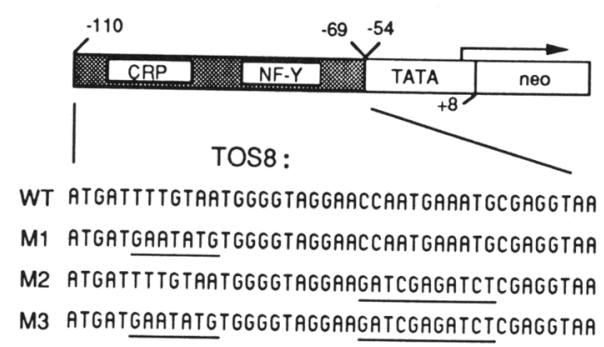

Internal Controls

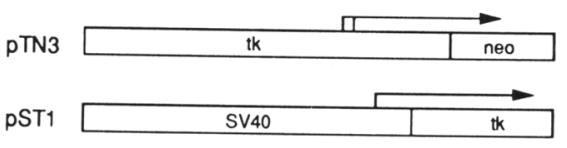

B

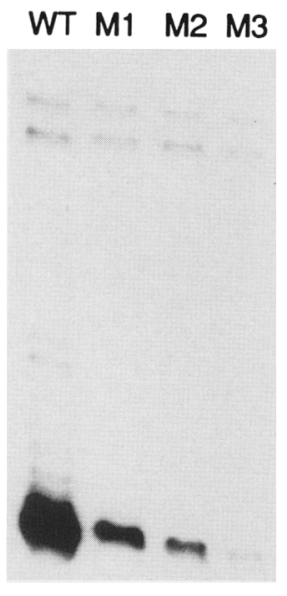

C

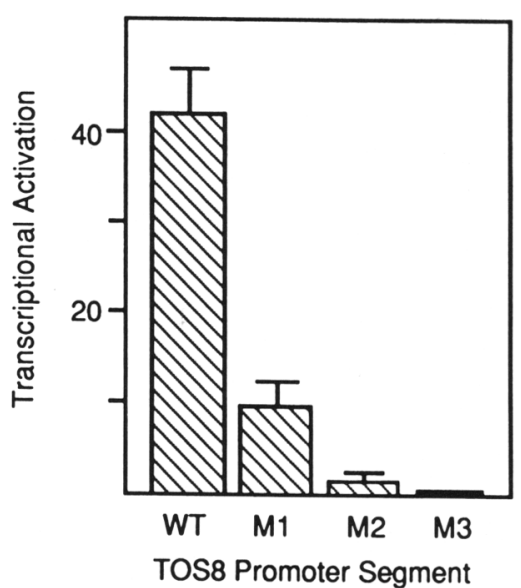

Figure 1. CRP and NF-Y synergistically activate transcription in liver nuclear extracts. $|A|$ The pTOS8 plasmids were created by linking an albumin promoter segment from -110 to -69 to the albumin TATA element and transcription start site $(-54$ to +8$)$ upstream of the bacterial neo gene. The wild-type (TOS8-WT) sequence is shown with TOS8-M1 and TOS8-M2, which contain mutations of either the CRP- or NF-Y-binding sites, respectively (mutated bases are underlined), and TOS8-M3, which contains mutations of both sites. All oligonucleotides had the sequence ATC added on their 5 ' ends. The internal control plasmids consisted of either the thymidine kinase $(t k)$ promoter from -80 to +58 upstream of the neo gene or the SV40 early promoter from -144 to +20 upstream of the $t k$-coding sequence. $(B)$ Transcriptional activities of the pTOS 8 plasmids were monitored in mouse liver nuclear extracts. The autoradiograph shows primer extension products of the transcription reactions. $(C)$ Quantitation of transcription signals from five independent experiments using the pTOS8-WT, pTOS8-M1, pTOS8-M2, and pTOS8-M3 plasmids. Transcriptional activation values represent fold stimulation over the activity of the pTOS8-M3 template, and error bars indicate standard deviation. The average activation values over M3 ( \pm S.D.) shown in $C$ are $42 \pm 5.2$ for WT, $9.7 \pm 2.7$ for M1, and $3.0 \pm 0.8$ for M2.

Wild-type competitor DNA (TOS8-WT) prevented the appearance of the C/Y complex, whereas the TOS8-M3 double mutant had no effect (Fig. 2B). The presence of excess TOS8-M1 competitor significantly reduced the appearance of the C/Y complex (see also Fig. 4, below), resulting in the C/EBP family-binding pattern. The TOS8-M2 competitor also prevented $\mathrm{C} / \mathrm{Y}$ formation and left a single discrete band at the NF-Y position. Taken together, the DNA-binding assays support the conclusion that the low-mobility $\mathrm{C} / \mathrm{Y}$ complex is the result of the simultaneous binding of the NF-Y and CRP factors.

As a control, similar mobility-shift assays were performed with spleen nuclear extracts, which lack CRP site-binding activity (Lichtsteiner et al. 1987). As shown in Figure 2C, the low-mobility $\mathrm{C} / \mathrm{Y}$ complex was absent; only the NF-Y complex was seen, which was only competed by intact NF-Y sites.

We then asked whether the $\mathrm{C} / \mathrm{Y}$ complex could be reconstituted with C/EBP protein expressed in bacteria and NF-Y isolated from a liver nuclear extract by affinity chromatography. As seen in Figure 2D, specific NF-Ybinding activity eluted in the $1 \mathrm{~m}$ salt fraction (lanes $3-5$ ), whereas the flowthrough contained negligible amounts (lanes 1 and 2). The $1 \mathrm{M}$ fraction was enriched significantly for the 32 - and $43-\mathrm{kD}$ subunits of NF-Y (Hooft van Huijsduijnen et al. 1990) as judged by silver staining of the material on an SDS gel (data not shown). The bacterially synthesized C/EBP protein formed a band with a slightly faster mobility than NF-Y (lanes
6-8). When the C/EBP protein was mixed with the affinity-purified NF-Y, the low-mobility C/Y complex was seen (lane 12). Although the formation of $C / Y$ was reproducible in purified fractions, the low concentrations of proteins appeared to favor individually bound proteinDNA complexes. In addition, bacterial C/EBP could lack a modification essential for efficient $\mathrm{C} / \mathrm{Y}$ complex formation. Importantly, the $\mathrm{C} / \mathrm{Y}$ complex did not form when the NF-Y affinity column flowthrough was mixed with C/EBP (lanes 9-11), and none of the proteins alone formed the low-mobility complex. We conclude that NF-Y and C/EBP can form a ternary complex with DNA.

\section{Alteration of DNA recognition properties when CRP and NF-Y form a ternary complex}

Methylation interference assays were used to determine whether there were different features of the DNA recognized by NF-Y and CRP when they bound DNA together versus independently. EMSAs were performed with a TOS8-WT probe that was treated with dimethylsulfate (DMS) and then incubated with either crude nuclear extracts or purified components. Specific bands were excised from the gel, sites of methylation were cleaved, and the products were applied to a sequencing gel.

To reveal CRP DNA-binding determinants in the absence of NF-Y, the EMSA reaction was performed with liver extracts in the presence of the TOS8-Ml competitor, and different upper and lower CRP gel-shift bands 
Figure 2. Ternary complex formation between CRP, NF-Y, and the albumin promoter. (A) EMSAs were performed with $7 \mu \mathrm{g}$ of liver nuclear extracts and radiolabeled TOS8-WT, TOS8-M1, and TOS8-M2 oligonucleotide probes. The positions of the NF-Y, CRP, and $\mathrm{C} / \mathrm{Y}$ complexes are shown at the sides of the autoradiograph. Protein-free DNA migrated to the bottom of the gel. $(B)$ TOS8-WT radiolabeled probe was incubated with $7 \mu$ g of liver nuclear extracts in the presence or absence of 75-fold molar excesses of unlabeled TOS 8 competitors (Comp) as indicated above each lane. Higher levels of competitor resulted in more efficient competition (Fig. 4). (C) EMSA with $7 \mu \mathrm{g}$ of spleen nuclear extracts. Competitor oligonucleotides were at a 75-fold molar excess. Higher levels of WT and M1 competitor led to the complete loss of NF-Y signal (data not shown). (D) Flowthrough (F.T.) fractions, or the high salt fractions (NF-Y) from the NF-Y DNA affinity column, and bacterially synthesized full-length C/EBP (obtained from W. Landschulz and S. McKnight) were used in EMSA with the TOS8-WT oligonucleotide and the designated competitors.
A

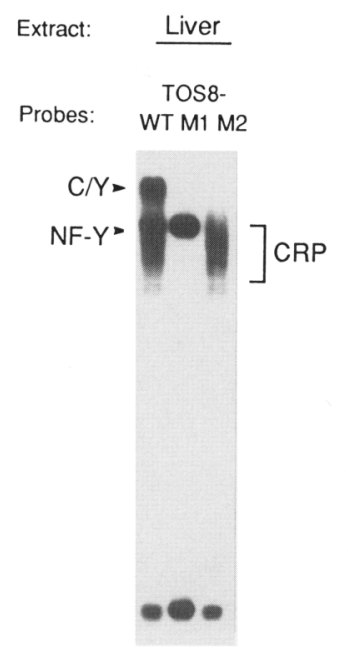

B

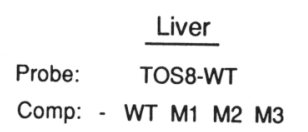

$\mathrm{C} / \mathrm{Y}=$
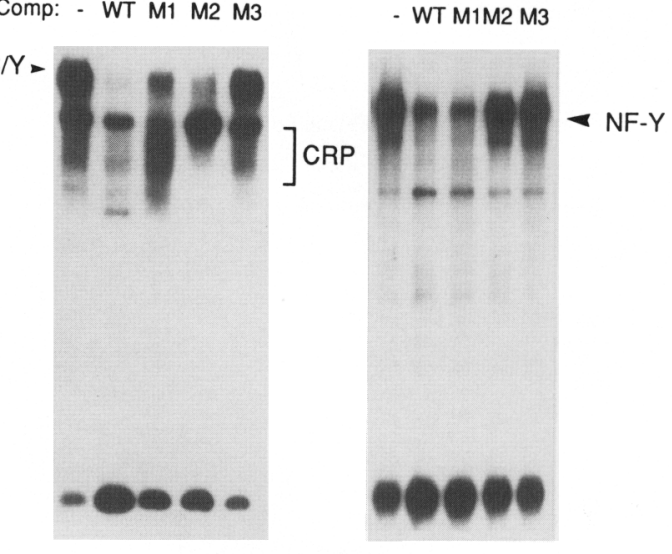

C

Spleen

TOS8-WT

- WT M1M2 M3
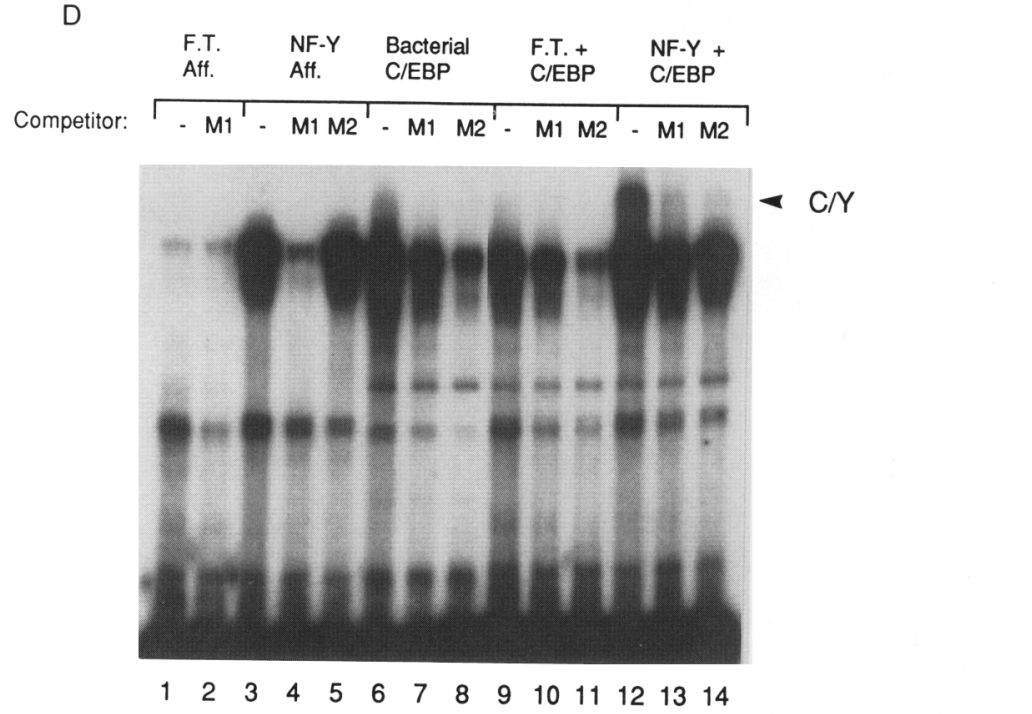

were analyzed (Fig. 3A,B, lanes $\mathrm{Cu}$ and $\mathrm{Cl}$ ). Methylation of the top-strand $G$ residues at -102 and -108 interfered with binding of CRPs when bound independently (lanes $\mathrm{Cu}$ and $\mathrm{Cl}$ ) or in the C/Y complex (the latter was performed with the TOS8-WT probe in the absence of competitor). As expected, bacterially synthesized C/EBP (Fig. $3 \mathrm{C}$, lane C) exhibited a methylation interference pattern identical to the $\mathrm{Cu}$ and $\mathrm{Cl}$ complexes from liver nuclear extracts. Formation of the CRP and C/Y complexes were equally sensitive to methylation of bottom-strand $A$ residues at positions -103 to -106 (Fig. 3B, lanes $\mathrm{Cu}$ and Cl). The binding interference data are summarized in Figure 3D; circles above and below the TOS8 sequence show the critical nucleotides. Also shown are residues that inhibit binding to probes that were partially depurinated with formic acid (triangles; data not shown; Brunelle and Schleif 1987). We note that CRP recognizes a sequence that is similar to a high-affinity C/EBP-binding site consisting of a dyad of the sequence GCAAT
(Vinson et al. 1989; Fig. 3D, arrows). The binding interference sites occur on the albumin promoter dyad in a pattern similar to that observed for C/EBP on other binding sites (Nye and Graves 1990).

NF-Y-binding activity was inhibited strongly by methylation of the top-strand $G$ residues at positions -82 , -90 , and -91 and slightly by methylation at top-strand positions -94 and -95 (Fig. 3A, lanes Y; Fig. 3D). Affinity-purified NF-Y exhibited an interference pattern identical to that seen in crude nuclear extracts (Fig. 3C, lane $\mathrm{Y}$ ). The $\mathrm{C} / \mathrm{Y}$ complex clearly contained the sum of the binding interference patterns observed with the NF-Y and CRP factors alone (Fig. 3A-C, lanes C/Y). Interestingly, however, there were subtle but reproducible losses in methylation sensitivity seen for certain NF-Y contacts in the ternary complex, on the basis of densitometry scanning of autoradiographs. Specifically, a 50\% decrease in methylation sensitivity was seen at topstrand positions -90 and -91 , and a $25 \%$ decrease in 
A

Liver

TOS8 Top Strand

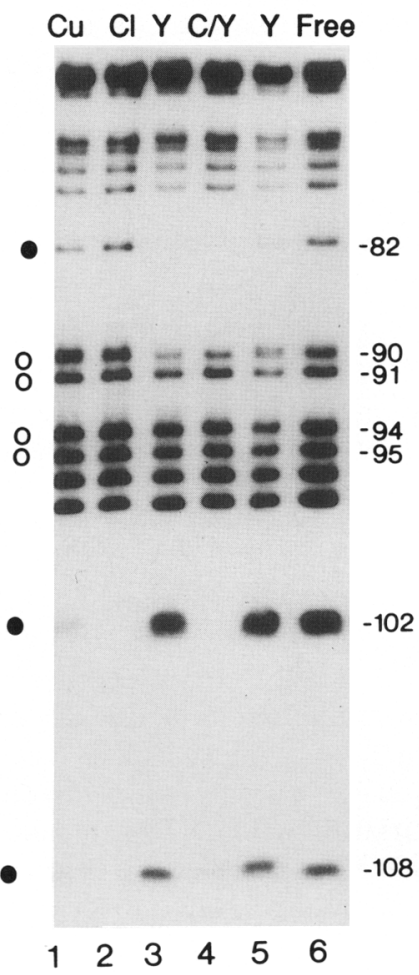

B

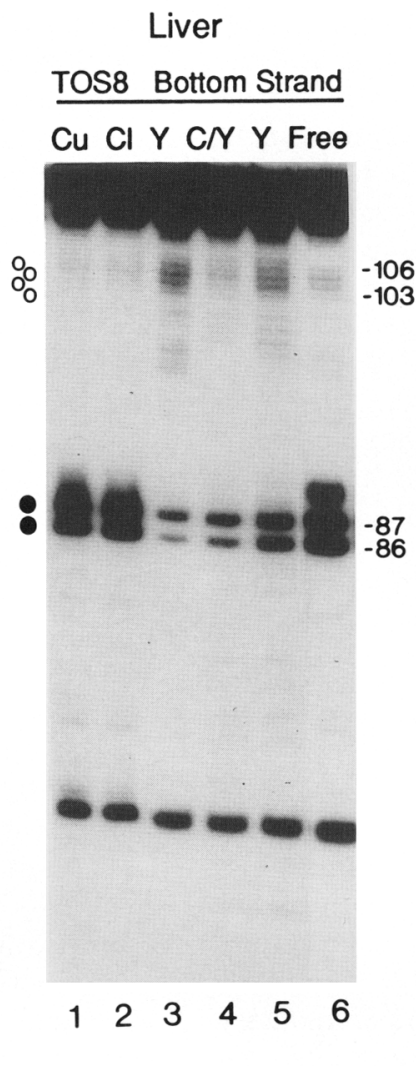

C

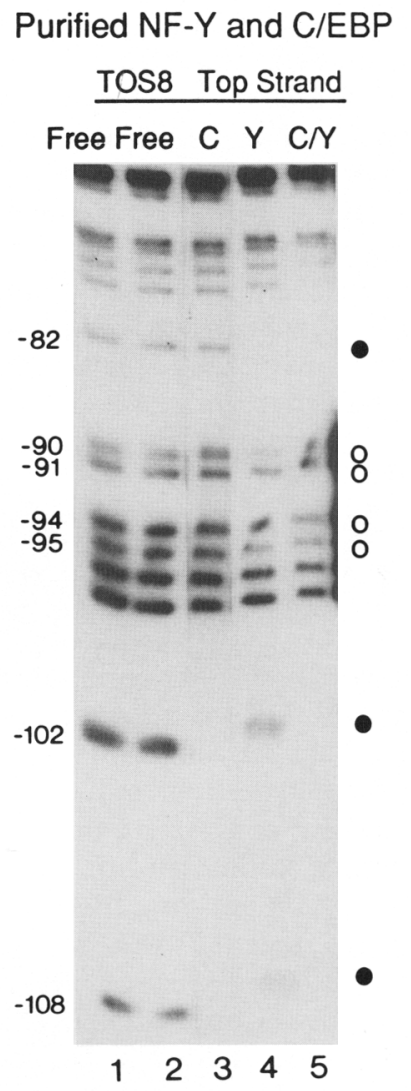

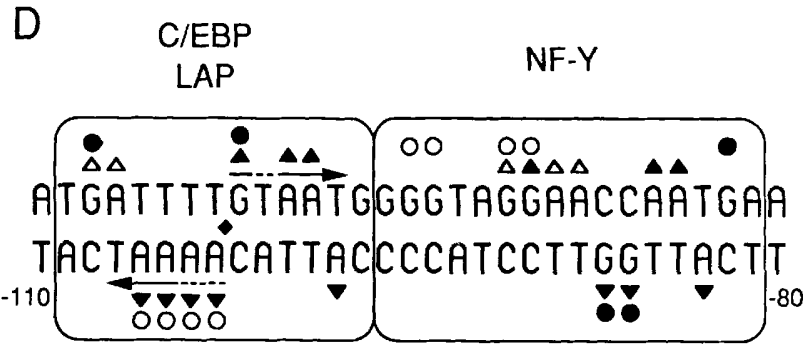

Figure 3. Altered binding site recognition in the CRP/NF-Y ternary complex. $\{A, B\}$ DMS interference with liver nuclear extracts. TOS8-WT probe that had been $5^{\prime}$ end-labeled on the top $(A, C)$ or bottom $(B)$ strand was partially methylated with DMS and used in gel-shift assays with liver nuclear extracts $(A, B)$ or with purified factors $|C|$, with or without competitor DNA. Complexes representing the low-mobility C/Y complex (no competitor), the CRP proteins $(\mathrm{Cu}$ and $\mathrm{Cl})$ (in the presence of the TOS8-M1 competitor), and NF-Y protein $(\mathrm{Y})$ (in the presence of TOS8-M2 competitor) were isolated, cleaved with piperidine, analyzed on a $12 \%$ sequencing gel, and autoradiographed. The CRP gel-shift smear (Fig. 2A) was divided into an upper portion $(\mathrm{Cu})$ and a lower portion $(\mathrm{Cl})$ for this analysis. For quantitative comparisons of methylation interference, sequencing lanes were scanned by laser densitometry from two separate experiments and compared with free DNA. $(C)$ DMS interference with purified factors. Bacterially synthesized C/EBP and affinity-purified NF-Y $(1 \mathrm{M} \mathrm{KCl}$ fraction) were bound independently or mixed together and analyzed as described above. $(D)$ Schematic representation of binding interference data. Methylation and depurination interference data are presented as circles and triangles, respectively, above or below the relevant bases of a portion of the TOS8 sequence. Solid circles and triangles indicate methylation or depurination sites, respectively, with the strongest inhibitory effects on binding. Arrows indicate position of a partially dyad symmetric sequence with similarity to a dyad of GCAAT, which comprises a strong C/EBP-binding site (Vinson et al. 1989); broken regions of the arrow indicate positions that lack similarity. The diamond indicates the center of the dyad.

methylation sensitivity was seen at positions -94 and -95 ; these NF-Y contact points are the closest to the CRP site. Apparently, the presence of CRP in the complex alters the conformation of the DNA, or of NF-Y, resulting in an alteration of the recognition properties of NF-Y. Although we have shown that the binding of CRP and NF-Y is not mutually exclusive, the data are consistent with the previously described "weakening" of the
NF-Y footprint in the presence of CRP (Cereghini et al. 1987; Lichtsteiner et al. 1987).

The binding interference studies suggested that increasing the spacing between the $\mathrm{pC}$ and $\mathrm{pD}$ sites could increase the binding ability of CRP and NF-Y. Accordingly, we inserted 5 or 10 bp between the essential recognition points determined by the DMS interference experiments in Figure 3D. Although the insertions did not 
alter the migration of the ternary complex or its ability to be competed by the various wild-type and mutant oligonucleotides, in an average of four experiments, the efficiency of $\mathrm{C} / \mathrm{Y}$ formation increased 2.3-fold for the TOS8-In5 sequence, compared with TOS8-WT, and increased 3.5-fold for TOS8-In 10 (Fig. 4). The amounts of ternary complex present at equilibrium were highly sensitive to the probe concentrations, but at each concentration of probe the insertion mutants formed the $\mathrm{C} / \mathrm{Y}$ complex to a greater extent than the wild-type DNA (data not shown). Because simply moving the binding sites farther apart increases binding, these experiments demonstrate that the close apposition of the factors on the wild-type promoter segment reduces their ability to bind DNA.

\section{CRP and NF-Y do not bind the TOS8 albumin promoter segment cooperatively}

The differences in relative binding ability between the wild-type and insertion mutations did not exclude the possibility that transcriptional synergism between CRP and NF-Y could be the result of cooperative DNA binding. To test for cooperative binding interactions, we assayed ternary complex formation at equilibrium in the presence of competitor DNA containing both intact binding sites, that is, TOS8-WT, to that of competitors containing binding sites on separate DNA fragments, that is, TOS8-M1 and TOS8-M2. TOS8-M3 competitor was added to the TOS8-WT competitor to normalize the mass of DNA. The oligonucleotides containing binding sites on separate fragments reproducibly competed the $\mathrm{C} / \mathrm{Y}$ ternary complex slightly better than the DNA fragment containing both binding sites (Fig. 5A).

The dissociation rate of the ternary complex with a TOS8-WT probe was then compared with the dissociation of NF-Y and CRP from TOS8-M1 and TOS8-M2, respectively (Fig. 5B). In an average of three experiments, the ternary complex dissociated with an average $t_{1 / 2}$ of
14.5 min, whereas CRP alone dissociated with a $t_{1 / 2}$ of 13 min and NF-Y alone with a $t_{1 / 2}$ of $16 \mathrm{~min}$. Experiments with the TOS8-In5 and TOS8-In 10 segments also failed to provide evidence for cooperative binding interactions between CRP and NF-Y (data not shown). Taken together, the results indicate that the $\mathrm{C} / \mathrm{Y}$ ternary complex formation does not involve cooperative DNA-binding interactions.

\section{CRPS require NF-Y for their ability to form stable preinitiation complexes at the albumin promoter}

We then considered the possibility that CRP and NF-Y interact synergistically after the DNA-binding step; therefore, we investigated the roles of the factors in the formation of stable preinitiation complexes at the promoter (for review, see Sawadogo and Sentenac 1990). Upstream binding factors have been shown to promote the formation of stable complexes at the TATA box and downstream by recruiting basal transcription factors such as TFIID (Hai et al. 1988; Horikoshi et al. 1988a,b) and TFIIB (Lin and Green 1991) to the template. Stable complexes can form on a DNA template that is preincubated with a transcription extract before the addition of NTP substrates. Stable complexes have formed if the subsequent addition of a competitor oligonucleotide does not inhibit initiation when NTPs are added to start the reaction. Competitors added at the beginning of the preincubation step should inhibit transcription by preventing upstream factors from binding to the template.

We preincubated transcription templates with liver nuclear extracts in the absence of added nucleotides at $31^{\circ} \mathrm{C}$ for $30-45 \mathrm{~min}$. Samples had no competitor added, competitor added at time zero, or competitor added after preincubation. Nucleotides were added after preincubation, just after competitor addition, and transcription proceeded for an additional $45 \mathrm{~min}$. In the experiment shown in Figure 6, stable complex formation was demonstrated by the ineffectiveness of a 120 -fold molar ex-

Figure 4. Inserting a full helical turn between CRPand NF-Y-binding sites increases ternary complex formation. Gel-shift assays were performed with $5 \mu \mathrm{g}$ of liver extract using TOS8-WT, TOS8-In5, and TOS8In 10 radiolabeled probes. Unlabeled competitors were added at a 125-fold molar excess.
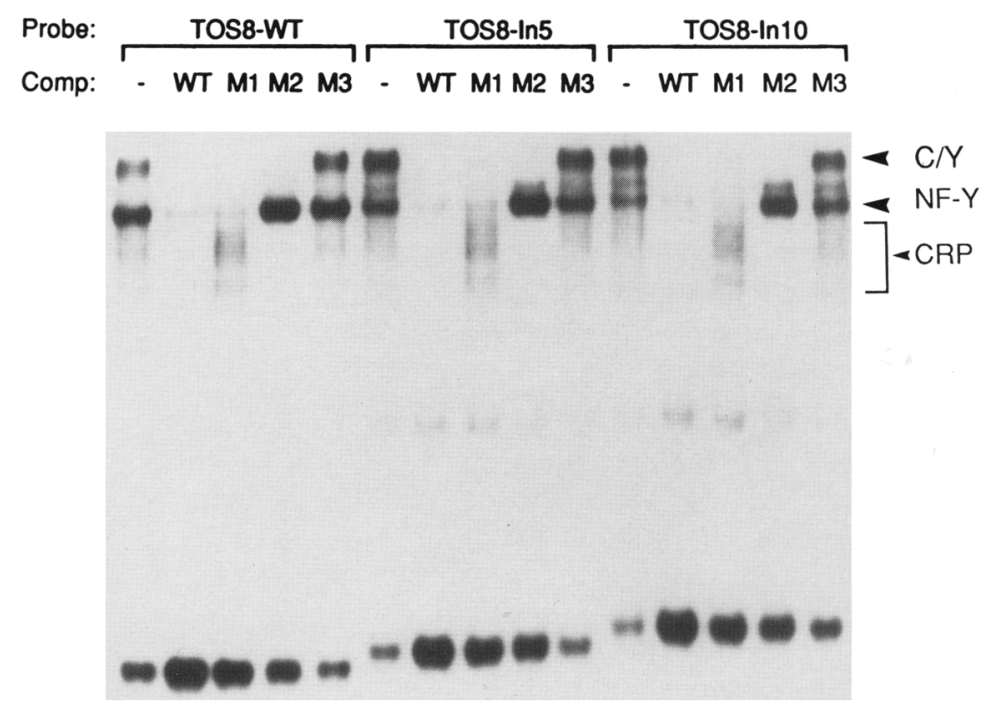
A

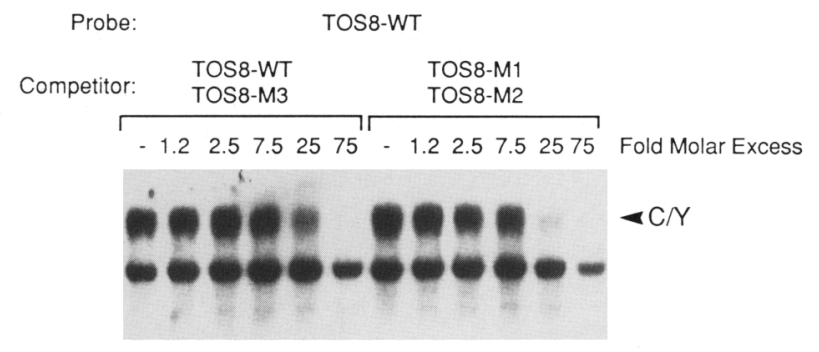

B

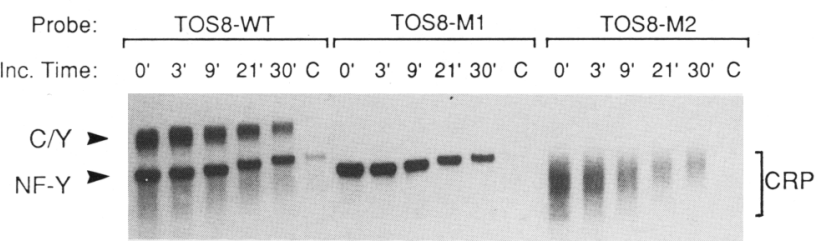

Figure 5. Lack of cooperative DNA binding by CRP and NF-Y. (A) Equilibrium binding experiments. Liver nuclear extracts were preincubated with poly[d(I-C)] for $20 \mathrm{~min}$. Labeled TOS8WT oligonucleotides were added followed immediately by the indicated molar excesses of TOS8-WT + TOS8-M3 or TOS8$\mathrm{M} 1$ + TOS8-M2 competitors. After $30 \mathrm{~min}$, the samples were loaded on a gel and electrophoresed. $(B)$ Dissociation experiments. Nuclear extracts were preincubated with poly[d(I-C)] for $20 \mathrm{~min}$, followed by the addition of $0.1 \mathrm{ng}$ of radiolabeled TOS8WT, TOS8-M1, or TOS8-M2 oligonucleotide. After a 30-min incubation, by which time binding equilibrium was reached, a 125-fold molar excess of unlabeled TOS8-WT competitor was added. Incubations continued for the number of minutes indicated above each lane, and samples were then loaded onto a running gel. Lane $C$ had competitor added at the same time as the radiolabeled oligonucleotide. DNA bound to protein was quantitated by densitometry and the $t_{1 / 2}$ of dissociation was determined by plotting the averages of three separate experiments. The $t_{1 / 2}$ values were as follows: C/Y, $14.5 \mathrm{~min}$; NF-Y, 16 min; CRP, 13 min.

cess of the TOS8-WT competitor, added after a $30 \mathrm{~min}$ preincubation, to inhibit transcription. When the TOS8WT competitor was added at time zero, transcriptional activity was reduced almost 10 -fold. Thus, we conclude that CRP or NF-Y, or both, participate in the formation of stable complexes. When Sarkosyl was added to $0.2 \%$ at different times after NTP addition to inhibit reinitiation events (Hawley and Roeder 1985, 1987; Reinberg et al. 1987), it reduced transcription to $12 \%$ of the control signal for the $30-\mathrm{sec}$ time point and to $24 \%$ of the control signal for the 60 - and 90 -sec time points. Therefore, less than one-quarter of the transcription signal from the pTOS8-WT template is the result of an initial round of transcription, compared with $\sim 75 \%$ of the signal being the result of multiple rounds of initiation by stable transcription complexes.

The formation of the stable preinitiation complex may require both CRP and NF-Y together, or each factor could form such a complex independently. In the case of the pTOS8-M1 template (Fig. 7A,B), which only binds
NF-Y, all of the transcriptional activity was refractory to TOS8-M1 competitor added after complex assembly, demonstrating that NF-Y alone can form stable preinitiation complexes. However, all of the transcriptional stimulation by the TOS8-M2 template, which only binds CRPs, was competed by TOS8-M2 competitor added after the preincubation step (Fig. 7C,D). All quantitations include normalization to the internal control signal in each lane, and the presence of a control HNF1 site competitor had no effect in either reaction (Fig. 7B,D). We conclude that CRP factors binding by themselves are unable to form a stable preinitiation complex.

We then defined the individual roles of NF-Y and CRP in complex formation with the pTOS8-WT template, containing both binding sites. When TOS8-M1 and TOS8-M2 competitor oligonucleotides were added separately at time zero, transcriptional activity was competed to $\sim 10 \%$ and $40 \%$, respectively, of the signal without competitor (Fig. 8). Some activation was still evident in the presence of these single-site competitors owing to the remaining factor not competed. The greater loss of

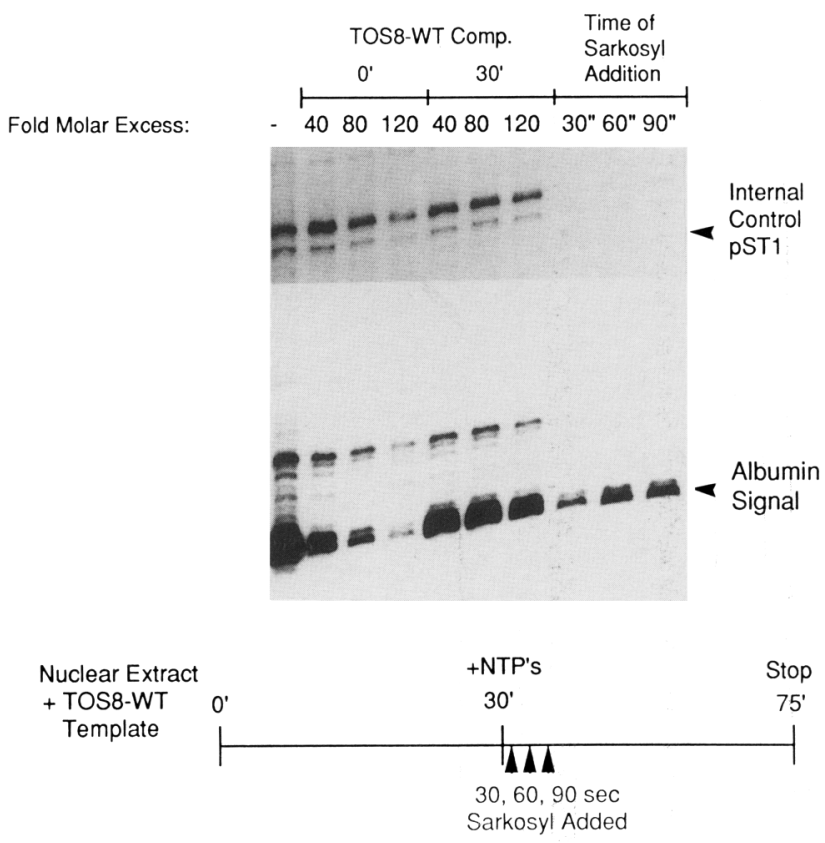

Figure 6. Strong transcriptional activity of the pTOS8-WT template results from reinitiation in vitro. Liver nuclear extracts were preincubated in the absence of added nucleotide for $30 \mathrm{~min}$. To assess the formation of stable preinitiation complexes, the indicated molar excesses of TOS8-WT competitor were added at 0 or $30 \mathrm{~min}$. After preincubation, nucleotides were added and the reactions were incubated for an additional $45 \mathrm{~min}$. When competitors were added after the preincubation, nucleotides were added before competitors, followed by competitor addition 20-30 sec later. Samples were also preincubated for $30 \mathrm{~min}$, and at times 30,60 , or $90 \mathrm{sec}$ after NTP addition, Sarkosyl was added to a final concentration of $0.2 \%$; these were followed by $45 \mathrm{~min}$ of further incubation. Primer extension products of the RNAs are shown. The pST1 control signal is evident in the Sarkosyl lanes with longer exposure. 
A

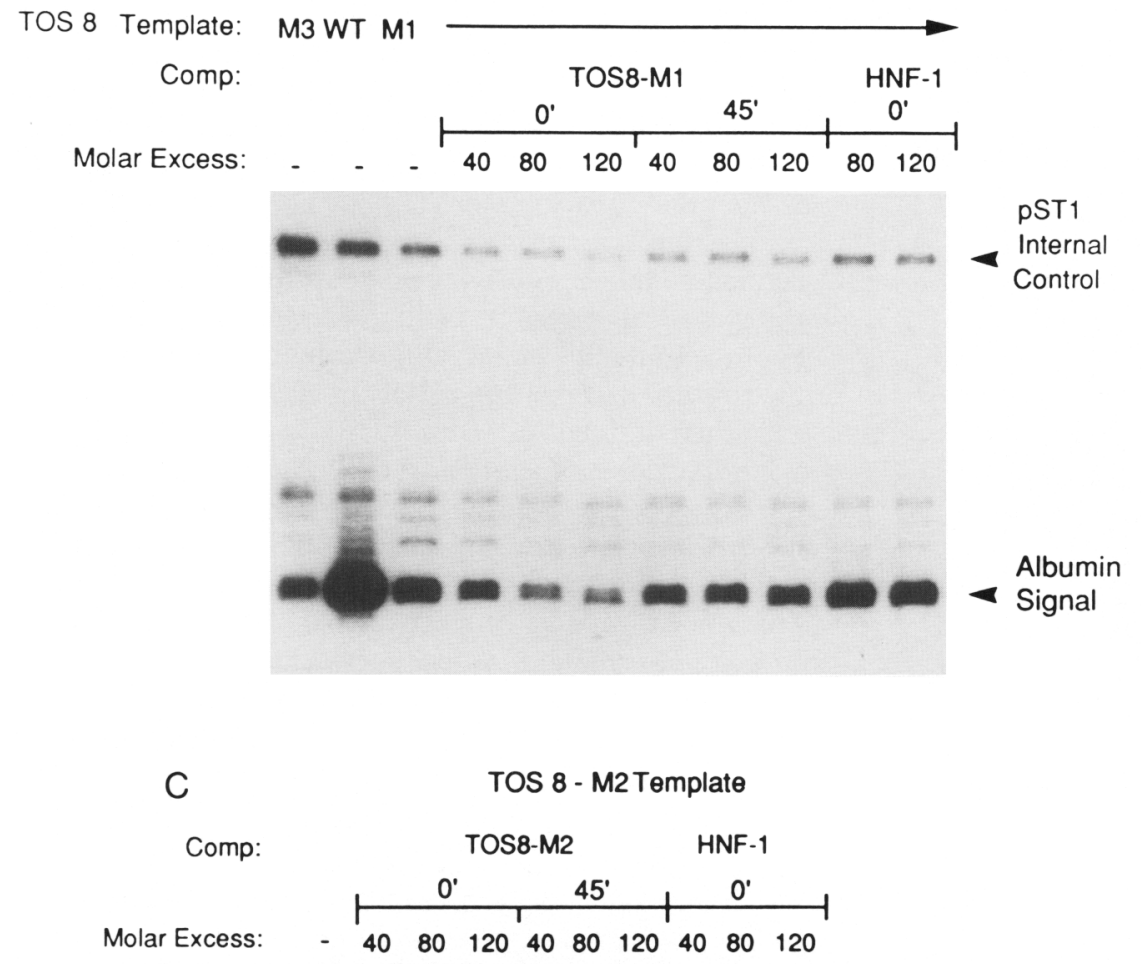

B
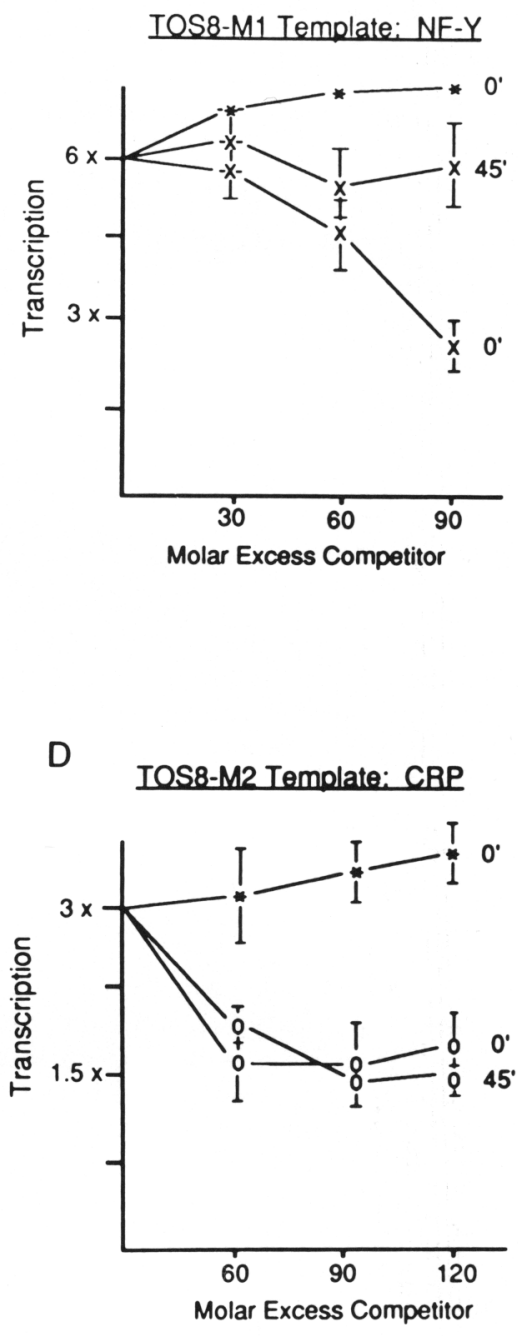

Figure 7. NF-Y, but not CRP, is able to form a stable preinitiation complex independent of the other factor. Stable complex experiments were performed with pTOS8-M1 $(A)$ and pTOS8-M2 $(C)$ templates and increasing molar excesses of homologous competitors (Comp). The HNF-1 oligonucleotide was used as a control. In these experiments, stable complex formation proceeded for 45 min before nucleotide addition. $(B, D)$ Quantitation of stable complex experiments with pTOS8-M1 and pTOS8-M2 templates, respectively. The observed transcriptional activation for each template with or without competitor was normalized to the internal control signal and expressed as a percentage of the pTOS8-WT signal. Averages of three independent experiments with two nuclear extract preparations are shown; error bars indicate standard error of the mean. $(B)(*)$ HNFl control; $(\times)$ TOS8-M1 (NF-Y). (D) $(*)$ HNFl control; (0) TOS8-M2 (CRP). TOS8-M1 effectively prevented transcriptional activation when the competitor was added before the preincubation but not after. TOS8-M2 effectively prevented activation of transcription when added both before and after the preincubation.

signal with the TOS8-M1 competitor, which competes for NF-Y, is consistent with the greater effect on transcription caused by disrupting the NF-Y-binding site on the TOS8-M2 template (Fig. 1C). Most experiments exhibited some inhibition of the internal control signal at high molar excesses with all competitors (Fig. 8A), but this nonspecific effect was accounted for when albumin signals were divided by control values for each point. When the competitors were added after a 45-min preincubation, $\sim 66 \%$ of the transcriptional activity was re- fractory to the TOS8-MI competitor (Fig. 8B, left) and $100 \%$ of the activity was refractory to the TOS 8 -M2 competitor (Fig. 8B, right). The HNF1 oligonucleotide added at either time zero $(0)$ or $45 \mathrm{~min}$ had no effect on transcription (Fig. 8A,B). Thus, both CRP and NF-Y participate effectively in stable complex formation when binding sites for both factors are present. Importantly, only in the presence of NF-Y do CRPs have a detectable ability to form stable preinitiation complexes (Fig. 8B, right). We conclude that transcriptional synergism be- 

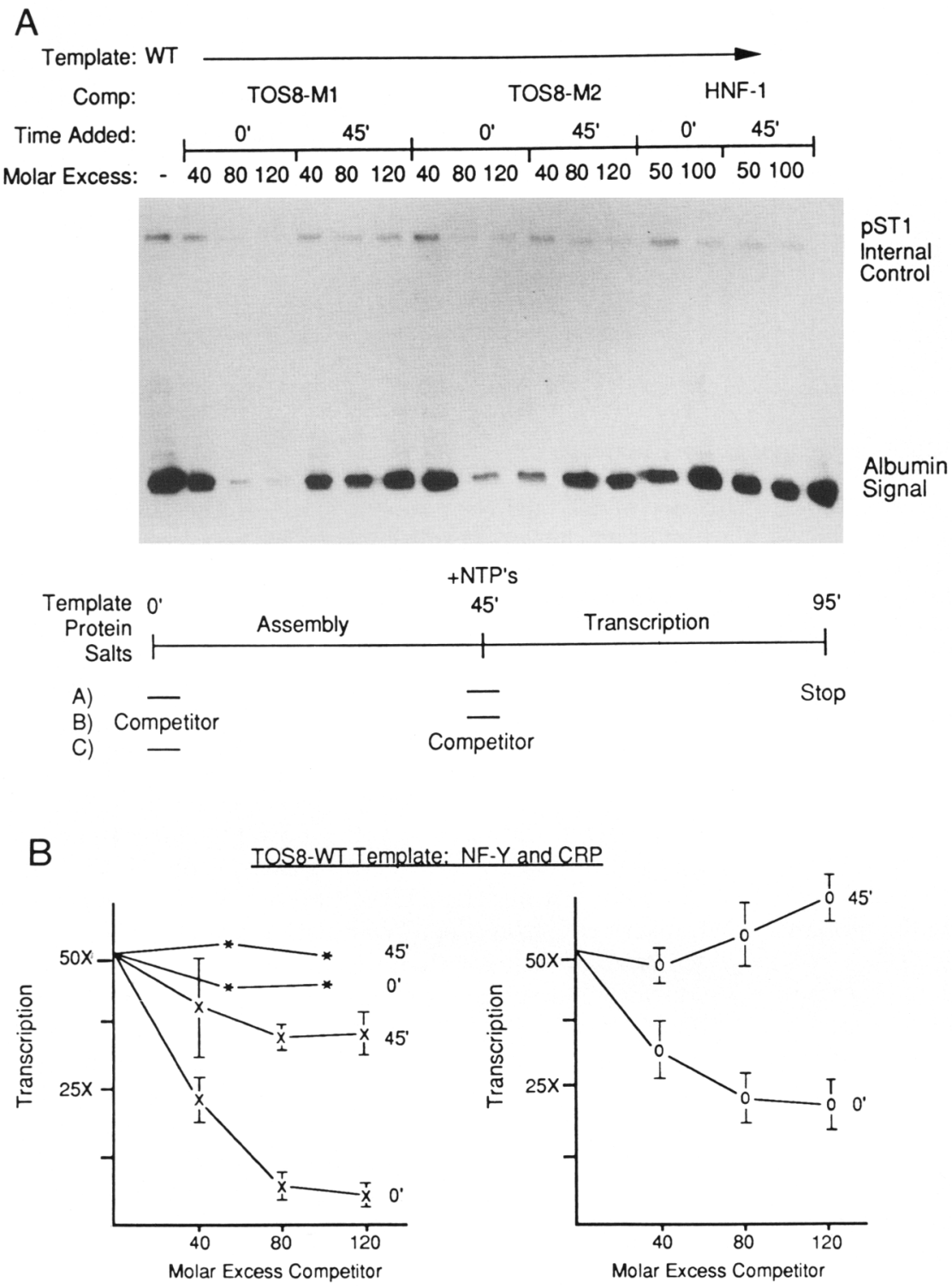

Figure 8. CRP and NF-Y participate in formation of a stable preinitiation complex. (A) Stable complex experiment with the pTOS8-WT template and the designated molar excesses of TOS8-M1, TOS8M2, and HNF1 oligonucleotides. Preincubation was for $45 \mathrm{~min}$. (B) Quantitation of stable complex experiments with the pTOS8-WT template and TOS8-M1 (left) or TOS8-M2 (right) competitors. Averages of three independent experiments with two nuclear extract preparations are shown; error bars indicate standard error of the mean. (Left) $(*)$ HNF1 control; $(x)$ TOS8-M1 (NF-Y). (Right) (0) TOS8-M2 (CRP). The molar excesses of the control HNFl competitor were not the same in all three experiments so one set of data is provided as a control. tween CRP and NF-Y is the result of the ability of NF-Y to facilitate or induce CRP to form stable complexes at the promoter.

Transcriptional synergism and efficient stable complex formation depend on precise positioning of CRP and NF-Y

To assess whether transcriptional synergism was dependent on CRP and NF-Y simply being present at their respective translational positions along the helix or whether their close positioning in the wild-type sequence was important, we tested the transcriptional activity of templates containing the TOS8-In5 and TOS8In10 insertion mutations. Surprisingly, inserting 5 bp reduced transcriptional activation to $50 \%$ of the pTOS 8 WT level, whereas inserting $10 \mathrm{bp}$ gave only the amount of activation observed for wild-type TOS8 (Fig. 9A,B), despite the fact that the insertion mutations caused an increase in CRP and NF-Y binding (Fig. 4). In addition, a TOS8-In 10 segment in the inverted orientation was less than half as active as In 10 in the correct orientation (data not shown), whereas the TOS8-WT segment functioned equally well in both orientations.

Addition of the TOS8-M2 competitor to a standard transcription reaction (without the preincubation step) reduced transcriptional stimulation from the pTOS 8 -WT template to an average of $22 \%$ of the wild-type signal (Fig. 9C), about the level seen by NF-Y alone with the pTOS8-M1 template (Fig. 1C). However, the same range of TOS8-M2 competitor only reduced transcriptional activation by pTOS 8 -In 10 template to an average of $73 \%$ of the wild-type signal (Fig. 9C). These findings indicate that at the start of the transcription reaction, CRP is bound more stably to the pTOS8-In10 template than to the pTOS8-WT template, which is consistent with the 
A

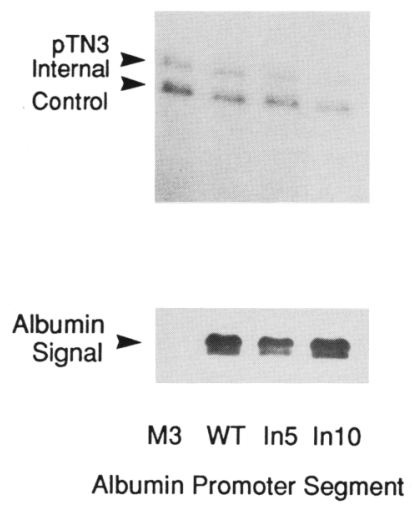

B

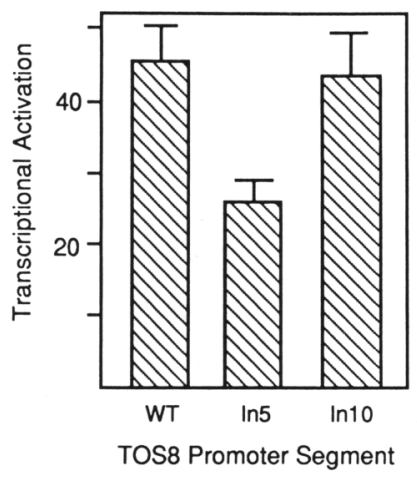

C

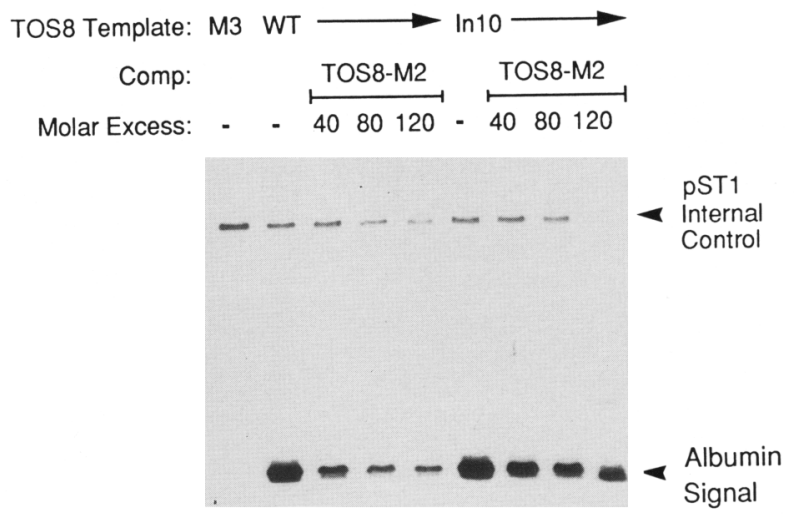

Figure 9. Transcriptional consequences of increasing the spacing between CRP- and NF-Y-binding sites. $(A)$ The transcriptional activity of the pTOS8-M3 and pTOS8-WT templates was compared with that of templates in which the spacing between the CRP and NF-Y factors had been increased by 5 (pTOS8-In5) or 10 (pTOS8-In10) bp. (B) Quantitation of five independent transcription assays with the pTOS8-M3, pTOS8-WT, pTOS8-In5, and pTOS8-In10 templates. Laser densitometry was used for quantitation, and activation over pTOS8-M3 is shown. The values were ( \pm S.E.M.): pTOS8-WT, $45 \times \pm 5.5$; pTOS8-In5, 27.6 $\pm 3.8 ;$ pTOS8-In10, 43.4× \pm 5.6 . (C) Increasing amounts of TOS8-M2 (CRP) competitor were used in transcription reactions with the pTOS8-WT and pTOS8-In10 templates. In two independent experiments, the competitors reduced transcription to an average of $22 \%$ and $73 \%$ with the WT and In 10 templates, respectively.

increase in heteromer formation seen with isolated In 10 oligonucleotide (Fig. 4). Thus, despite a threefold increase in stable binding of CRP to the pTOS8-In10 template, transcription was not increased above the pTOS8WT level.

Importantly, we have shown that the lack of increased activation with pTOS8-In10 is not the result of limiting amounts of binding or accessory factors, because using twice as much plasmid template gave twice the transcription signal, and when the HNFl-binding site was fused to the albumin TATA element, it gave significantly greater activation than the pTOS8-WT template (data not shown). Thus, the albumin TATA element was not saturated by the level of activation from the TOS8WT or TOS8-In 10 elements. We conclude that CRPs optimally contribute to transcriptional activation when positioned immediately adjacent to the NF-Y-binding site and when NF-Y binding is altered.

Given that we found transcriptional synergism between CRP and NF-Y to occur during the formation of stable transcription complexes, an additional experiment was performed to investigate the stability of complexes on the pTOS8-In10 template. If the increased binding of CRP and NF-Y to the pTOS8-In10 template resulted in the formation of complexes that were more stable through multiple rounds of transcription, then a greater proportion of the transcription signal would be inhibited by Sarkosyl, because Sarkosyl inhibits reinitiation events. If CRP and NF-Y on the pTOS8-In10 template were less efficient in forming stable complexes, then more of the transcription signal would be resistant to Sarkosyl. When the pTOS8-In10 template was preincubated with a liver nuclear extract for $45 \mathrm{~min}$ before the addition of nucleotides and Sarkosyl was added (to $0.2 \%$ ) $60 \mathrm{sec}$ after nucleotide addition, the resulting transcrip- tional signal was, on average, $\sim 1.5$-fold greater than the signal from the pTOS8-WT template (Table 1); the values were not significantly different. We conclude that transcription from the pTOS8-In 10 template is not more sensitive to Sarkosyl than the wild-type template. Thus, considering the increased binding efficiency of CRP and NF-Y on pTOS8-In10, the factors are less efficient in maintaining basal factors at the promoter. Apparently, the precise positioning of CRP and NF-Y on the wildtype promoter is optimal for the liver-enriched factors to participate in stable complex formation.

Table 1. Sarkosyl sensitivity of transcription templates after stable complex formation

\begin{tabular}{lcc}
\hline Txn. + Sarkosyl & $\begin{array}{l}\text { Average values }^{\mathrm{a}} \\
(\times 100 \%)\end{array}$ & $\begin{array}{c} \pm \text { S.D. } \\
(\times 100 \%)\end{array}$ \\
\hline Txn. - Sarkosyl & $14 \%$ & $\pm 4.6 \%$ \\
\hline pTOS8-WT/pSTl + Sarkosyl & $21 \%$ & $\pm 8.5 \%$ \\
\hline pTOS8-WT/pST1 - Sarkosyl & & \\
\hline
\end{tabular}

Transcription templates were preincubated with liver nuclear extracts for $45 \mathrm{~min}$ in the absence of nucleotides, to permit stable complex formation. Nucleotides were then added and, 60 sec later (in the + Sarkosyl samples), Sarkosyl was added to $0.2 \%$. Transcription reactions continued for an additional 50 min and were analyzed as shown in Fig. 1B. Transcription signals of comparable band intensities from different autoradiographic exposures were quantitated by laser densitometry. Each pTOS8 signal was normalized to the pST1 signal in the same lane, and values from samples containing Sarkosyl were divided by samples lacking Sarkosyl.

${ }^{a}$ Average values were calculated from experiments with four different preparations of liver nuclear extracts and two different preparations of plasmid. 


\section{Discussion}

We investigated protein interactions at the serum albumin promoter to begin to understand how the overall composition and orientation of binding factors determines promoter activity and cell specificity. We find that a single CRP factor, comprised of a dimer of C/EBP, of LAP/IL6-DBP, or a heterodimer of the two (Descombes et al. 1990; Poli et al. 1990; Cao et al. 1991; Williams et al. 1991), is by itself only weakly able to stimulate the basic transcriptional machinery when bound to the albumin promoter $\mathrm{pD}$ site and is unable to contribute to the formation of complexes that are stable through multiple rounds of transcription. CRP binding alone could weakly stimulate transcription either by directly (but not stably) recruiting basal factors or by preventing nonspecific inhibitors such as histone $\mathrm{Hl}$ from binding to the template (Croston et al. 1991). The binding of NF-Y to the adjacent $\mathrm{pC}$ site alters CRP, or the close apposition of NF-Y and CRP creates a qualitatively different protein surface or protein-DNA conformation, so that CRP can now contribute to the formation of stable preinitiation complexes (Fig. 10).

Why is the activity of CRP at a single $\mathrm{pD}$ site exquisitely sensitive to the presence of NF-Y at the $\mathrm{pC}$ site when multimers of the $\mathrm{pD}$ site can efficiently stimulate transcription in the absence of pC (Maire et al. 1989; Descombes et al. 1990; Poli et al. 1990|? Many studies of multimerization have revealed a nonlinear increase in transcriptional activation as the number of binding sites increases, indicating cooperative interactions (Ondek et al. 1987; Schirm et al. 1987; Fromental et al. 1988). In contrast, the data of Maire et al. (1989) indicate that transcriptional stimulation by CRPs in liver nuclear extracts increases linearly with increasing numbers of $\mathrm{pD}$ sites. Thus, it appears that CRPs require other factors for synergistic effects on transcription, similar to what has been described for certain "enhanson" elements of the SV40 enhancer (Fromental et al. 1988; Ondek et al. 1988).

The insertion of $10 \mathrm{bp}$ between the $\mathrm{pC}$ and $\mathrm{pD}$ sites caused a threefold increase in the ability of CRP and NF-Y to bind DNA together, without a concomitant increase in transcription. A decrease in transcription was observed for the inverted TOS8-In10 segment, whereas the TOS8-WT segment functioned as well in both orientations. Furthermore, stable complex formation did not increase with the pTOS8-In10 template, despite increased binding of factors to the TOS8-In 10 element. We therefore conclude that although increasing the spacing between the two factors reduced, but did not eliminate, transcriptional synergism, synergism in stable complex formation is optimal with a specific, direct interaction between CRP and NF-Y. Our findings with pTOS8-In10 show that synergism does not necessarily occur by simple targeting of the transcriptional activation domains of the two proteins (Friedman and McKnight 1990; Hooft van Huijsduijnen et al. 1990) to different positions on the DNA that are rotationally related about the long axis (for discussion of this latter possibility, see Takahashi et al. 1986; Carey et al. 1990; Lin et al. 1990).
The synergism between CRP and NF-Y on the wildtype template appears not to be at the level of cooperative DNA binding, because no such cooperation was found in direct assays and because increasing $\mathrm{C} / \mathrm{Y}$ ternary complex formation with pTOS8-In 10 resulted in a decrease in synergism. It is possible that the wild-type complex of CRP and NF-Y is selectively stabilized by a third, possibly non-DNA-binding factor (or factors) in the transcription reaction. Such a stabilizing factor, which could be a component of the basal transcription machinery, would bind efficiently to the structure created in the $\mathrm{C} / \mathrm{Y}$ ternary complex and less so to factors on the pTOS8-In 10 template.

Interestingly, we found a subtle but reproducible alteration in the DNA recognition properties of NF-Y in the wild-type $\mathrm{C} / \mathrm{Y}$ ternary complex. We interpret these findings to suggest that the apposition of CRP next to NF-Y alters the conformation of the protein or DNA, or of both, which could play an important role in recruiting basic transcription factors to the promoter. The fact that synergism was observed with the TOS8 sequence in either orientation (Fig. 1 and data not shown) demonstrates that there must not be strict spatial constraints on how the $\mathrm{C} / \mathrm{Y}$ complex interacts with basal transcription factors. Our model may be relevant to the recent observations of Oliviero and Struhl (1991), who recently found that the number of proteins bound to a promoter, rather than the number of acidic activation domains, could be important for transcriptional synergism between recombinant proteins that bind noncooperatively to a tandem site. Our findings would suggest that specific interactions between proteins, leading to conformational changes, may be necessary to alter the affinity for basal factors to stimulate transcription.

We therefore propose that the ubiquitous NF-Y factor

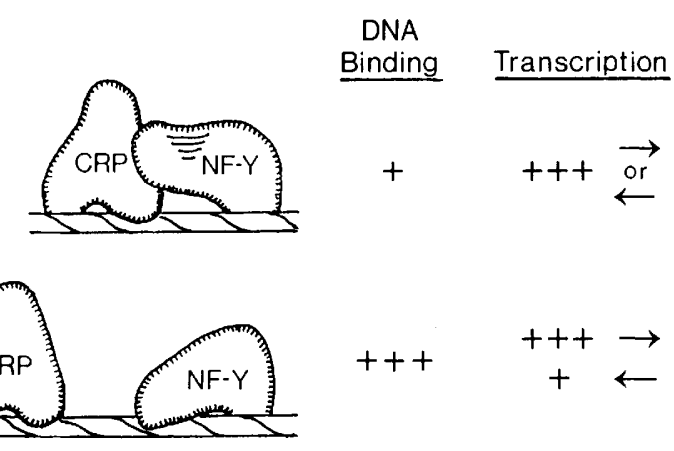

Figure 10. Model for synergistic transcriptional activation by CRP and NF-Y. A single CRP binding as a dimer of itself, or as a heterodimer between C/EBP and LAP/NF-IL6, is shown as a single species binding to the albumin promoter $\mathrm{pD}$ site, with NF-Y binding to the adjacent $\mathrm{pC}$ site. The close juxtaposition of the two factors alters the binding of NF-Y while causing CRP to participate efficiently in the formation of stable transcription complexes. The transcriptional synergism is manifested with the DNA segment in either orientation (arrows). Moving the CRP- and NF-Y-binding sites $10 \mathrm{bp}$ apart increases the ability of both proteins to bind stably to the DNA but reduces stable complex formation and transcriptional synergism. 
plays a newly discovered and important role in the cell specificity of the serum albumin promoter; it permits the liver-enriched factors C/EBP and LAP/IL6-DBP to form stable transcription complexes. The synergistic effects, together with the contributions of other hepatic factors binding to the albumin promoter and enhancer, lead to the high rate of transcription of the gene in adult hepatocytes. Our findings also provide an attractive model to explain the sharp increase in albumin gene transcription at birth (Tilghman and Belayew 1982; Panduro et al. 1987). Both NF-Y mRNA (Hooft van Huijsduijnen et al. 1990) and pC site-binding activity (S. Cascio and $\mathrm{K}$. Zaret, unpubl.) are present in mouse embryos at day 10 of gestation, the time by which liver formation and albumin transcription have just begun (Cascio and Zaret 1991), but CRP factors do not appear until just before birth (Birkenmeier et al. 1989; Descombes and Schibler 1991). In the fetal stage, the ability of NF-Y to form stable preinitiation complexes could keep the promoter in an open chromatin configuration, active at a low level, and poised for the appearance of CRPs. The interaction of CRPs with NF-Y would dramatically enhance the recruitment of basal factors and thereby stimulate transcription.

Ultimately, explaining how all six upstream factors interact with one another over a 150-bp region of the albumin promoter will require an understanding of the three-dimensional orientation of the proteins on DNA (discussed in Echols 1986), as well as their cooperative roles in recruiting the basal transcriptional machinery (Hai et al. 1988; Horikoshi et al. 1988a,b; Lin and Green 1991). The work described here on one segment of the albumin promoter should facilitate future studies in understanding how these and additional factors interact at higher hierarchical levels.

\section{Materials and methods}

\section{Oligonucleotide and plasmid constructs}

TOS8 oligonucleotides (Fig. 1) were synthesized with a Biosearch 8600 Synthesizer, purified by gel electrophoresis, and annealed to create double-stranded molecules that were filled in at the ends with Klenow polymerase. All DNA concentrations were quantitated by both optical density and ethidium bromide staining of acrylamide gels with varying amounts of oligonucleotide. These were used directly for binding assays or ligated to the pAN6 vector (see legend to Fig. 1) to generate the pTOS8 derivatives. The structures of all plasmid constructs were verified by DNA sequencing. The sequence 5 -GGACT was inserted in the In 5 oligonucleotide, and 5'-GGACTGGACT was inserted in the In 10 oligonucleotide, between the -97 - and -98-bp position of the TOS8 sequence.

\section{In vitro transcription assays}

Transcription extracts were prepared in the morning (to eliminate the effects of DBP; Mueller et al. 1990) from 6-month-old male mice essentially as described by Gorski et al. (1986) and Maire et al. (1989), except that nuclei were pelleted through the $2 \mathrm{~m}$ sucrose cushion and then immediately resuspended in nuclear lysis buffer. Cell-free transcription reactions were per- formed similar to those of Gorski et al. (1986), except for the following modifications: Reactions typically included $45 \mu \mathrm{g}$ of liver nuclear extract, $100 \mathrm{ng}$ of pTN3 or pST1, and $200 \mathrm{ng}$ of pTOS8 plasmids (isolated from the dam ${ }^{-}$Escherichia coli strain GM2163 and purified on two sequential CsCl gradients) and a final concentration of $9.75 \mathrm{mM} \mathrm{MgCl}_{2}, 8 \mathrm{mM}$ creatine phosphate, $50 \mathrm{~mm} \mathrm{KCl}, 600 \mu \mathrm{M}$ NTPs, $25 \mathrm{~mm}$ HEPES (pH 7.6), $12 \%$ glycerol, and 30 units of RNase inhibitor (BMB or Ambion) in a $20-\mu l$ volume. The $\mathrm{MgCl}_{2}$ concentration was titrated from 6 to $12 \mathrm{mM}$ for each extract preparation. Reactions were carried out at $31-32^{\circ} \mathrm{C}$ for $50 \mathrm{~min}$ and stopped by the addition of a $300-\mu \mathrm{l}$ solution containing $0.3 \mathrm{M} \mathrm{NaOAc}(\mathrm{pH} 7.0), 0.2 \%$ SDS, and $10 \mu \mathrm{g}$ of tRNA. Proteinase $\mathrm{K}$ was added to a concentration of $250 \mu \mathrm{g} / \mathrm{ml}$; the reaction was incubated for $10 \mathrm{~min}$ at room temperature and extracted with $400 \mu \mathrm{l}$ of phenol/chloroform (9:1). The aqueous layer was saved, and nucleic acid was precipitated with $760 \mu$ l of ice-cold $95 \%$ ethanol with $1 \mathrm{mM}$ PMSF added. RNA was pelleted and rinsed with cold $70 \%$ ethanol. Kinased neo primer $\left(0.5 \times 10^{6}\right.$ to $\left.1.5 \times 10^{6} \mathrm{cpm} / \mathrm{ng}\right)$ was hybridized to the RNA and extended using reverse transcriptase (Liu et al. 1988). Primer extension products were analyzed on a sequencing gel followed by autoradiography. Lack of ribonucleotide addition to the transcription reaction resulted in no primer extension product. Transcription signals were quantitated by laser scanning densitometry (LKB Ultroscan XL) of at least two different autoradiographic exposures of each experiment. Transcriptional activation values are expressed as the average fold stimulation over the pTOS8-M3 value / the latter being equal to one and are shown \pm S.D. For each average value, data were compiled from at least two separate nuclear extract preparations and two different plasmid preparations.

For the stable complex experiments, transcription reactions were preincubated without NTPs for $30-45 \mathrm{~min}$. Competitors were added after preincubation, followed 15-20 sec later by the addition of prewarmed NTPs. The observed transcriptional activation for each template, with or without competitor, was normalized to the internal control and expressed as a percentage of the wild-type signal. Averages of three stable complex experiments are shown in Figure 8B. A 4\% solution of Sarkosyl was prepared and added to a final concentration of $0.2 \%$ for the transcription experiment in Figure 6.

\section{EMSAs and protein-DNA contact analysis}

EMSAs were performed with nuclear extracts as described by Liu et al. (1988), with the following modifications: Reaction volumes were $15 \mu \mathrm{l}$, containing between 5 and $7 \mu \mathrm{g}$ of liver or spleen nuclear extract, $0.1 \mathrm{ng}$ of TOS 8 probe $\left(1 \times 10^{7} \mathrm{cpm} / \mathrm{ng}\right)$, and 1-2 $\mu \mathrm{g}$ of poly[d(I-C) (Pharmacia). Nucleoprotein complexes were resolved in $6 \%$ acrylamide gels containing $0.5 \times$ TBE buffer. For contact analysis, TOS8-WT oligonucleotides that had been $5^{\prime}$-end-labeled on the top or bottom strand were partially methylated with DMS at $37^{\circ} \mathrm{C}$ for $3 \mathrm{~min}$ (Liu et al. 1991) or partially depurinated by incubation with formic acid at room temperature for $14 \mathrm{~min}$ (Brunelle and Schleif 1987). A standard EMSA was performed; protein-DNA complexes and free DNAs were isolated, cleaved with piperidine, and analyzed on a $12 \%$ denaturing polyacrylamide gel (Liu et al. 1991). The radioactivity present in relevant bands was quantitated by laser densitometry.

\section{Affinity purification of NF-Y}

A large-scale preparation of a dog liver nuclear extract was chromatographed on a heparin agarose column. The $0.3 \mathrm{M}$ fraction, which contained the NF-Y-binding activity las judged by 
EMSA|, was passed over a DNA oligonucleotide affinity column (Kadonaga and Tiian 1986) containing multimers of the specific oligonucleotide 5'-CTCGGGGTAGGAACCAATGAAACTC$3^{\prime}$. Bound material was eluted in $0.3 \mathrm{M}, 1 \mathrm{M}$, and $1.5 \mathrm{M}$ steps with the majority of the NF-Y activity eluting in the $1 \mathrm{M} \mathrm{KCl} \mathrm{frac-}$ tion. The flowthrough and $1 \mathrm{~m}$ eluates were dialyzed and used for the experiments in Figures 2 and 3.

\section{Acknowledgments}

We thank Kim Stevens for the plasmid pAN6, Bill Landschulz and Steve McKnight for providing C/EBP protein, and Yehudit Bergman, John Burch, Peter Johnson, Trey McPherson, and Jerry Workman for helpful comments on the work. The work was funded by grants to K.Z. from the National Institutes of Health (GM36477) and Pfizer Central Research.

The publication costs of this article were defrayed in part by payment of page charges. This article must therefore be hereby marked "advertisement" in accordance with 18 USC section 1734 solely to indicate this fact.

\section{References}

Babiss, L.E., R.S. Herbst, A.L. Bennett, and J.E. Darnell Jr. 1987. Factors that interact with the rat albumin promoter are present both in hepatocytes and other cell types. Genes \& Dev. 1: 256-267.

Birkenmeier, E.H., B. Gwynn, S. Howard, J. Jerry, J.I. Gordon,W.H. Landschulz, and S.L. McKnight. 1989. Tissue-specific expression, developmental regulation, and genetic mapping of the gene encoding CCAAT/enhancer binding protein. Genes \& Dev. 3: 1146-1156.

Brunelle, A. and R.F. Schleif. 1987. Missing contact probing of DNA-protein interactions. Proc. Natl. Acad. Sci. 84: 66736676.

Cao, Z., R.M. Umek, and S.L. McKnight. 1991. Regulated expresssion of three C/EBP isoforms during adipose conversion of 3T3-L cells. Genes \& Dev. 5: 1538-1552.

Carey, M., Y.-S. Lin, M.R. Green, and M. Ptashne. 1990. A mechanism for synergistic activation of a mammalian gene by GAL4 derivatives. Nature 345: 361-365.

Cascio, S. and K.S. Zaret. 1991. Hepatocyte differentiation initiated during endodermal-mesenchymal interaction prior to liver formation. Development 113: 217-225.

Cereghini, S., M. Raymondjean, A. Garcia-Carranca, P. Herbomel, and M. Yaniv. 1987. Factors involved in control of tissue-specific expression of the albumin gene. Cell 50: 627638.

Cereghini, S., M. Blumenfeld, and M. Yaniv. 1988. A liver-specific factor essential for albumin transcription differs between differentiated and dedifferentiated rat hepatoma cells. Genes \& Dev. 2: 957-974.

Courtois, G., S. Baumhueter, and G.R. Crabtree. 1988. Purifiedhepatocyte nuclear factor 1 interacts with a family of hepatocyte-specific promoters. Proc. Natl. Acad. Sci. 85: 79377941.

Croston, G.E., L.A. Kerrigan, L.M. Lira, D.R. Marshak, and J.T. Kadonaga. 1991. Sequence-specific antirepression of histone H1-mediated inhibition of basal RNA polymerase II transcription. Science 251: 643-649.

Descombes, P. and U. Schibler. 1991. A liver-enriched transcriptional activator protein, LAP, and a transcriptional inhibitory protein, LIP, are translated from the same mRNA. Cell 67: 569-579.

Descombes, P., M. Chojkier, S. Lichtsteiner, E. Falvey, and U.
Schibler. 1990. LAP, a novel member of the C/EBP gene family, encodes a liver-enriched transcriptional activator protein. Genes \& Dev. 4: 1541-1551.

Echols, H. 1986. Multiple DNA-protein interactions governing high-precision DNA transactions. Science 233: 1050-1056.

Frain, M., G. Swart, P. Monaci, A. Nicosia, S. Stampfli, R. Frank, and R. Cortese. 1989. The liver-specific transcription factor LF-B1 contains a highly diverged homeobox DNA binding domain. Cell 59: 145-157.

Friedman, A.D. and S.L. McKnight. 1990. Identification of twopolypeptide segments of CCAAT/enhancer-binding protein required for transcriptional activation of the serum albumin gene. Genes \& Dev. 4: 1416-1426.

Fromental, C., M. Kanno, H. Nomiyama, and P. Chambon. 1988. Cooperativity and hierarchical levels of functional organization in the SV40 enhancer. Cell 54: 943-953.

Gorski, K., M. Carneiro, and U. Schibler. 1986. Tissue-specific in vitro transcription from the mouse albumin promoter. Cell 47: 767-776.

Hai, T., M. Horikoshi, R.G. Roeder, and M. Green. 1988.Analysis of the role of the transcription factor ATF in the assembly of a functional preinitiation complex. Cell 54: 10431051.

Hawley, D.K. and R. Roeder. 1985. Separation and partial characterization of three functional steps in transcription initiation by human RNA polymerase II. J. Biol. Chem. 260: 8163-8172.

- 1987. Functional steps ininitiation and reinitiation from the major late promoter in a HeLa nuclear extract. I. Biol. Chem. 262: 3452-3461.

Herbomel, P., A. Rollier, T. Francois, M.-O. Ott, M. Yaniv, and M.C. Weiss. 1989. The rat albumin promoter is composed of six distinct positive elements within 130 nucleotides. Mol. Cell. Biol. 9: 4750-4758.

Herbst, R.S., N. Friedman, J.E. Darnell, Jr., and L.E. Babiss.1989. Positive and negative regulatory elements in the mouse albumin enhancer. Proc. Natl. Acad. Sci. 86: 1553-1557.

Hooft van Huijsduijnen, R.H., X.Y. Li, D. Black, H. Matthes, C. Benoist, and D. Mathias. 1990. Co-evolution from yeast to mouse: cDNA cloning of the two NF-Y (CP-1/CBF) subunits. EMBO I. 9: 3119-3127.

Horikoshi, M., M.F. Carey, H. Kakidani, and R.G. Roeder.1988a. Mechanism of action of a yeast activator: Direct effect of GAL4 derivatives on mammalian TFIID-promoter interactions. Cell 54: 665-669.

Horikoshi, M., T. Hai, Y.S. Lin, M.R. Green, and R.G. Roeder. 1988b. Transcription factor ATF interacts with the TATA factor to facilitate establishment of a preinitiation complex. Cell 54: 1033-1042.

Johnson, P.F., W.H. Landschulz, B.J. Graves, and S.L. McKnight. 1987. Identification of a rat liver nuclear protein that binds to the enhancer core element of three animal viruses. Genes \& Dev. 1: 133-146.

Kadonaga, J.T. and R. Tjian. 1986. Affinity purification of sequence-specific DNA binding proteins. Proc. Natl. Acad. Sci. 83: 5889-5893.

Landschulz, W.H., P.F. Johnson, and S.L. McKnight. 1988. The leucine zipper: A hypothetical structure common to a new class of DNA binding proteins. Science 240: 1759-1764.

Lichtsteiner, S., J. Wuarin, and U. Schibler. 1987. The interplay of DNA-binding proteins on the promoter of the mouse albumin gene. Cell 51: 963-973.

Lin, Y.-S. and M.R. Green. 1991. Mechanism of action of an acidic transcriptional activator in vitro. Cell 64: 971-981.

Lin, Y.-S., M. Carey, M. Ptashne, and M.R. Green. 1990. How different eukaryotic transcriptional activators can cooperate 
promiscuously. Nature 345: 359-361.

Liu, J.-K., Y. Bergman, and K.S. Zaret. 1988. The mouse albumin promoter and a distal upstream site are simultaneously DNaseI hypersensitive in liver chromatin and bind similar liver-abundant factors in vitro. Genes \& Dev. 2: 528-541.

Liu, J.-K., C.M. DiPersio, and K. Zaret. 1991. Extracellular signals that regulate liver transcription factors during hepatic differentation in vitro. Mol. Cell. Biol. 11: 773-784.

Maire, P., J. Wuarin, and U. Schibler. 1989. The role of cis-acting elements in tissue-specific albumin gene transcription. Science 244: 343-346.

Maity, S.N., T. Vuoro, and B. deCrombrugghe. 1990. The B subunit of a new heteromeric CCAAT-binding transcription factor shows a striking sequence identity with the yeast Hap2 transcription factor. Proc. Natl. Acad. Sci. 87: 53785382.

Mueller, C.R., P. Maire, and U. Schibler. 1990. DBP, a liver enriched transcriptional activator is expressed late in ontogeny and its tissue-specificity is determined post-transcriptionally. Cell 61: 279-291.

Nye, J.A. and B.J. Graves. 1990. Alkylation interference identifies essential DNA contacts for sequence-specific binding of the eukaryotic transcription factor C/EBP. Proc. Natl. Acad. Sci. 87: 3992-3996.

Olesen, J.T. and L. Guarente. 1990. The HAP2 subunit of yeastCCAAT transcriptional activator contains adjacent domains for subunit association and DNA recognition: Model for the HAP2/3/4 complex. Genes \& Dev. 4: 1714-1729.

Oliviero, S. and K. Struhl. 1991. Synergistic transcriptional enhancement does not depend on the number of acidic activation domains bound to the promoter. Proc. Natl. Acad. Sci. 88: 224-228.

Ondek, B., A. Shepard, and W. Herr. 1987. Discrete elements within the SV40 enhancer region display different cell-specific enhancer activities. EMBO J. 6: 1017-1025.

Ondek, B., L. Gloss, and W. Herr. 1988. The SV40 enhancer contains two distinct levels of organization. Nature 333: 4045.

Ott, M.-O., L. Sperling, P. Herbomel, M. Yaniv, and M. Weiss.1984. Tissue-specific expression is conferred by a sequence from the $5^{\prime}$ end of the rat albumin gene. EMBO $\%$. 3: 2505-2510.

Panduro, A., F. Shalably, and D.A. Shafritz. 1987. Changing patterns of transcriptional and post-transcriptional control of liver specific gene expression during rat development. Genes \& Dev. 1: 1172-1182.

Pinkert, C.A., D.M. Ornitz, R.L. Brinster, and R.D. Palmiter. 1987. An albumin enhancer located $10 \mathrm{~kb}$ upstream functions along with its promoter to direct efficient, liver-specific expression in transgenic mice. Genes \& Dev. 1: 268276.

Poli, V., F.P. Mancini, and R. Cortese. 1990. IL-6DBP, a nuclear protein involved in interleukin-6 signal transduction, defines a new family of leucine zipper proteins related to C/EBP. Cell 63: 643-653.

Raymondjean, M., S. Cereghini, and M. Yaniv. 1988. Several distinct "CCAAT" box binding proteins coexist in eukaryotic cells. Proc. Nat1. Acad. Sci. 85: 757-761.

Reinberg, D., M. Horikoshi, and R.G. Roeder. 1987. Factors involved in specific transcription in mammalian RNA polymerase II. Functional analysis of initiation factors IIA and IID and identification of a new factor operating at sequences downstream of the initiation site. I. Biol. Chem. 262: 33223330 .

Sawadogo, M. and A. Sentenac. 1990. RNA polymerase B (II) and general transcription factors. Annu. Rev. Biochem. 59: 711-
754.

Schirm, S., J. Jiricny, and W. Schaffner. 1987. The SV40 enhancer can be dissected into multiple segments each with a different cell type specificity. Genes \& Dev. 1: 65-74.

Takahashi, K., M. Vigeron, H. Matthes, A. Wildeman, M. Zenke, and P. Chambon. 1986. Requirement of stereospecific alignments for initiation from the simian virus 40 early promoter. Nature 319: 121-126.

Tilghman, S.M. and A. Belayew. 1982. Transcriptional control of the murine albumin/ $\alpha$-fetoprotein locus during development. Proc. Natl. Acad. Sci. 79: 5254-5257.

Vinson, C.R., P.B. Sigler, and S.L. McKnight. 1989. Scissors-grip model for DNA recognition by a family of leucine zipper proteins. Science 246: 911-916.

Williams, S.C., C.A. Cantwell, and P.F. Johnson. 1991. A family of C/EBP-related proteins capable of forming covalently linked leucine zipper dimers in vitro. Genes \& Dev. 5: 15531567.

Wuarin, J., C. Mueller, and U. Schibler. 1990. A ubiquitous CCAAT factor is required for efficient in vitro transcription from the mouse albumin promoter. I. Mol. Biol. 214: 865874.

Zaret, K.S., C.M. DiPersio, D.A. Jackson, W.J. Montigny, and D.L. Weinstat. 1988. Conditional enhancement of liver-specific gene transcription. Proc. Natl. Acad. Sci. 85: 90769080 . 


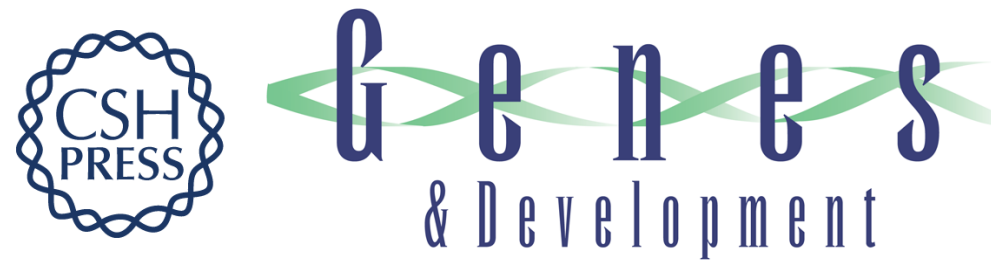

\section{A ubiquitous factor is required for C/EBP-related proteins to form stable transcription complexes on an albumin promoter segment in vitro.}

P M Milos and K S Zaret

Genes Dev. 1992, 6:

Access the most recent version at doi:10.1101/gad.6.6.991

References This article cites 55 articles, 34 of which can be accessed free at: http://genesdev.cshlp.org/content/6/6/991.full.html\#ref-list-1

License

Email Alerting Service

Receive free email alerts when new articles cite this article - sign up in the box at the top right corner of the article or click here.

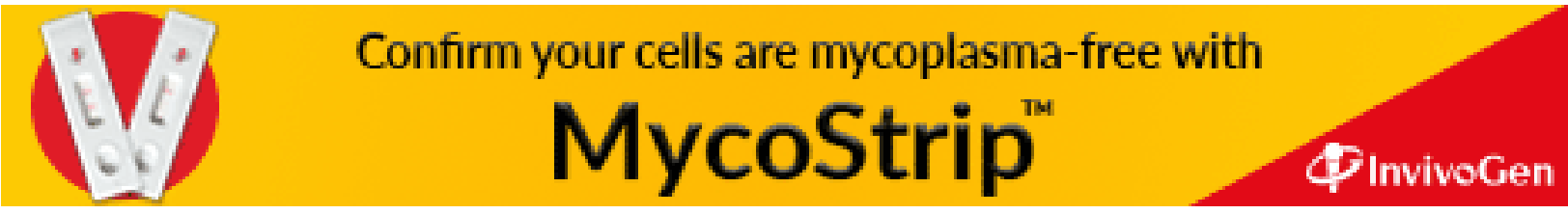

